\title{
Impact of COPD in patients with lung cancer and advanced disease treated with chemotherapy and/or tyrosine kinase inhibitors
}

This article was published in the following Dove Press journal:

International Journal of COPD

30 September 2014

Number of times this article has been viewed

José Luis Izquierdo

Pilar Resano

Abdulkader El Hachem

Desiré Graziani

Carlos Almonacid

Ignacio M Sánchez

Pulmonology Department, Guadalajara University Hospital, Guadalajara, Spain

Correspondence: José Luis Izquierdo Servicio de Neumología, Hospital Universitario de Guadalajara, C/Donante de sangre sn, 19002 Guadalajara, Spain $\mathrm{Tel}+349492019200$ ext 6947I

Fax +34949209218

Email jlizquierdo@sescam.org
Abstract: While it is relatively well known that the prognosis of patients with lung cancer (LC) treated with surgery is worse in the presence of chronic obstructive pulmonary disease (COPD), it is unknown if this assessment can be extrapolated to patients with advanced disease treated with chemotherapy and/or tyrosine kinase inhibitors. The aim of our study is to analyze the clinical characteristics and survival rates in patients with LC and COPD, and to compare these to the patients without airflow obstruction. From 471 evaluable patients, 324 (69\%) were not treated with surgery due to disseminated disease (stages 3B and 4). Of them, 47.7\% also had COPD. All patients were treated at the moment of diagnosis according to National Comprehensive Cancer Network guidelines with platinum-based chemotherapy or tyrosine kinase inhibitors. Kaplan-Meier curves showed no significant differences in overall survival between COPD and non-COPD patients $(\log -$ rank $P=0.65)$. In the multivariate Cox proportional hazard model adjusting for the most relevant variables, the adjusted hazard ratio $\left(\mathrm{HR}_{\text {adj }}\right)$ was statistically significant for performance status $\left(\mathrm{HR}_{\mathrm{adj}}=1.33,95 \%\right.$ confidence interval [CI]: 1.11-1.59; $P=0.002)$ and clinical stage $\left(\mathrm{HR}_{\text {adj }}=0.67,95 \% \mathrm{CI}: 0.50-0.89 ; P=0.006\right)$, but not for COPD status $\left(\mathrm{HR}_{\mathrm{adj}}=1.20,95 \% \mathrm{CI}: 0.83-1.50 ; P=0.46\right)$. Our conclusion is that at present, when using standard care in advanced LC (stages $3 \mathrm{~B}$ and 4), COPD does not have a significant deleterious impact on overall survival.

Keywords: lung cancer, chronic obstructive pulmonary disease, extended disease, chemotherapy, survival

\section{Introduction}

Approximately 10\%-15\% of chronic smokers get lung cancer (LC) and around 20\% develop chronic obstructive pulmonary disease (COPD). Age, smoking history, and impaired lung function have been identified as key risk factors, although host susceptibility factors cannot been excluded. Cross-sectional studies show that the prevalence of COPD is around 50\% of those diagnosed with LC, although the prevalence might change depending on the patient's age, sex, and smoking exposure. ${ }^{1-5}$

In recent decades, it has been described that COPD is an indicator of greater risk of respiratory complications and that it significantly increases the risk of cardiac arrhythmias and supraventricular tachycardia in patients undergoing lung resection surgery. ${ }^{6-8}$ For this reason, it is not surprising that the assessment of COPD in patients with LC has great interest mainly in patients eligible for surgery, since the mortality rates are significantly higher in patients with LC who have other pulmonary comorbidities and therefore higher risk of postoperative pulmonary complications..$^{9,10}$ So far, most LC studies regarding COPD have been focused on the early stages of 
the disease, trying to prevent complications and mortality related to surgery. ${ }^{9,11,12}$

Despite these advances in surgery and the introduction of new radiotherapy techniques on these days, most LC patients are being treated with chemotherapy or new tyrosine kinase inhibitors, which is the standard treatment for most patients with LC regardless of whether they have COPD. ${ }^{13}$ While it is relatively well recognized that after resection, the prognosis of those with COPD is worse than that of those without COPD, ${ }^{10,14}$ in patients with LC not subject to surgery due to advanced stages of the cancer, it is unknown whether COPD impacts in the prognosis when they are treated with chemotherapy and/or tyrosine kinase inhibitiors.

The objective of our study is to analyze the clinical characteristics and survival rates in patients with LC and COPD, and to compare these to the patients without airflow obstruction.

\section{Materials and methods Study subjects}

Patients with LC (number $[\mathrm{n}]=471$ ) were consecutively recruited between January 2006 and October 2013 following referral to a specialist LC clinic at a local tertiary hospital (Guadalajara, Spain). These patients were older than 35 years (range: $35-95$ years), and the diagnosis was confirmed by histological or cytological specimens in all cases. Nonsmokers with LC were also included, and those cases of primary $\mathrm{LC}$ with the following pathological diagnoses were finally selected for analysis: adenocarcinoma; squamous cell carcinoma; small cell cancer; and nonsmall cell lung cancer (not otherwise specified, including large cell carcinoma).

Spirometry was performed as recommended by the American Thoracic Society. We used postbronchodilator spirometry (MasterLab; Jaëger AG, Würzburg, Germany) and subjects were classified as having COPD according to Global Initiative for Chronic Obstructive Lung Disease (GOLD) staging with a ratio of forced expiratory volume in 1 second (FEV1) to forced vital capacity (FEV1/FVC) of $<0.7$. Predicted values for lung function variables are from the European Community for Coal and Steel. ${ }^{15}$

Each subject's information was recorded using a standardized database that included demographics, pulmonary function tests, image techniques, blood analysis, type of tumor, anatomical extension, treatment side effects, and survival. The patients with complete information during follow-up were finally included for analysis. The patients with poor performance status (Eastern Cooperative Oncology Group score 4) for which only the best supportive care was recommended, and those who moved from our city during follow-up were excluded. All included patients gave their informed consent before entry into the database, and the study was approved by the local ethics committee (Guadalajara Ethics Committee, Guadalajara, Spain).

For this study, we focused our analysis on patients with advanced stages at diagnosis without surgery (stages 3B and 4). Patients with early-stage cancer and surgical treatment were not included in the study. All of the patients were treated according to GOLD guidelines for $\mathrm{COPD}^{16}$ and according to the National Comprehensive Cancer Network guidelines, regardless of whether they had COPD. ${ }^{13}$ In most cases, first-line therapy included cisplatin or carboplatin in combination with any of the following agents: paclitaxel; gemcitabine (squamous carcinoma); etoposide (small cell carcinoma); or pemetrexed (patients with nonsquamous histology). For further lines, we personalized the drug regimen with the highest likelihood of benefit, and toxicity was deemed acceptable to both the physician and the patient. The agents that target the epidermal growth factor receptor pathway were the initial systemic treatment for the patients in whom a driver mutation was identified.

\section{Statistical analysis}

All statistical analyses were performed using SPSS version 20 (IBM Corporation, Armonk, NY, USA). Continuous variables were described by the measures of central tendency and dispersion (mean, standard deviation, median, and extreme values), by discrete variables, by frequency tables, and by the percentage over the total. The demographic and clinical variables for the patients are summarized as a description of the clinical profile.

The primary analysis was based on a log-rank test of the difference between the two groups with no adjustments for baseline covariates. Cox proportional hazards models were used to adjust for age, sex, tumor stage, performance status, smoking status, and GOLD stage. The main outcome was overall survival from the time of diagnosis. Statistical significance was set at $P<0.05$.

\section{Results}

From 471 evaluable patients, 324 (69\%) were not treated with surgery because of the disseminated disease (stages $3 \mathrm{~B}$ and 4). Among them $47.7 \%$ also had COPD (50.4\% in the overall population) with GOLD stage $1(35.6 \%)$ and stage $2(47.6 \%)$ predominance. Table 1 summarizes the clinical characteristics of the study population with LC according to COPD status. At the time of cancer diagnosis, COPD patients were older ( $70 \pm 10$ years versus $66 \pm 13$ years; $P=0.002$ ), but there 
Table I Demographic and clinical characteristics of the study population

\begin{tabular}{llll}
\hline $\mathbf{n = 3 2 4}$ & $\begin{array}{l}\text { Non-COPD } \\
\mathbf{( 5 2 . 3 \% )}\end{array}$ & $\begin{array}{l}\text { COPD } \\
\mathbf{( 4 7 . 7 \% )}\end{array}$ & P-value \\
\hline Age (years) & $66 \pm 13$ & $70 \pm 10$ & 0.002 \\
Sex (male) & $90 \%$ & $85 \%$ & $0.5 \mathrm{I}$ \\
Pack/years & $43 \pm 34$ & $51 \pm 33$ & 0.06 \\
Never smoking (\%) & $1 \mathrm{II}$ & 2.9 & 0.005 \\
Karnofsky & $67 \pm 34$ & $65 \pm 3 \mathrm{I}$ & 0.87 \\
ECOG & $0.8 \pm 0.8$ & $1 \pm 0.9$ & $\mathrm{NS}$ \\
Stage 3B (\%) & $38 \%$ & $42 \%$ & 0.58 \\
Stage 4 (\%) & $62 \%$ & $58 \%$ & \\
FEVI (L) & $2.10 \pm 0.74$ & $1.56 \pm 0.47$ & $<0.00 \mathrm{I}$ \\
FEVI (\%) & $81 \pm 24$ & $63 \pm 16$ & $<0.00 \mathrm{I}$ \\
FVC (L) & $2.67 \pm 0.94$ & $2.71 \pm 0.74$ & 0.89 \\
FVC (\%) & $79 \pm 33$ & $85 \pm 19$ & 0.08 \\
GOLD stage & & & \\
I & & $35.6 \%$ & \\
2 & & $47.6 \%$ & \\
3 & & $14.4 \%$ & \\
4 & & $2.4 \%$ &
\end{tabular}

Abbreviations: $n$, number; COPD, chronic obstructive pulmonary disease; ECOG, Eastern Cooperative Oncology Group; NS, not significant; FEVI, forced expiratory volume in I second; FVC, forced vital capacity; GOLD, Global Initiative for Chronic Obstructive Lung Disease.

were no significant differences in terms of sex distribution, performance status, or histological subtype distribution (Figure 1A). In COPD patients, there was a nonsignificant trend of a higher percentage of adenocarcinomas in GOLD 1 and squamous cell carcinoma in GOLD 2 (Figure 1B).

We looked at the correlation between the degree of airflow limitation in the entire study population; Pearson's correlation coefficient between FEV1, as the percent of the predicted value, and overall survival was very low $(r=0.12)$, suggesting that collateral factors rather than the degree of airflow limitation are the main elements responsible for the prognosis of these patients.

Kaplan-Meier curves showed no significant differences in overall survival between COPD and non-COPD patients ( $\log$-rank, $P=0.65$ ) (Figure 2).

In the Cox regression model, performance status (hazard ratio $[\mathrm{HR}]=1.32,95 \%$ confidence interval [CI]: 1.17-1.50; $P=0.000)$, clinical stage (3B versus 4$)(\mathrm{HR}=0.61,95 \% \mathrm{CI}$ : $0.48-0.78 ; P=0.000)$, and histological type ( $\mathrm{HR}=1.22,95 \%$ CI: $1.011 .46 ; P=0.04)$ were significantly associated with poor overall survival. In the multivariate Cox proportional hazard model adjusting for the most relevant variables, the adjusted HR was statistically significant for performance status $\left(\mathrm{HR}_{\mathrm{adj}}=1.33,95 \% \mathrm{CI}: 1.11-1.59 ; P=0.002\right)$ and clinical stage $\left(\mathrm{HR}_{\mathrm{adj}}=0.67,95 \% \mathrm{CI}: 0.50-0.89 ; P=0.006\right)$, but not for COPD status $\left(\mathrm{HR}_{\text {adj }}=1.20,95 \%\right.$ CI: $0.83-1.50$; $P=0.46$ ) (Table 2).

\section{Discussion}

In the present study, we found that in using standard care in patients with LC and advanced disease (stages 3B and 4), the presence of COPD did not worsen the prognosis. COPD also has little impact on the main characteristics of the patient at diagnosis, and it does not have a significant deleterious impact in terms of overall survival.

In last few years, great advances have been made in the areas of COPD and LC. Genetic studies seem to point to shared susceptibility genes that are common to COPD and
A

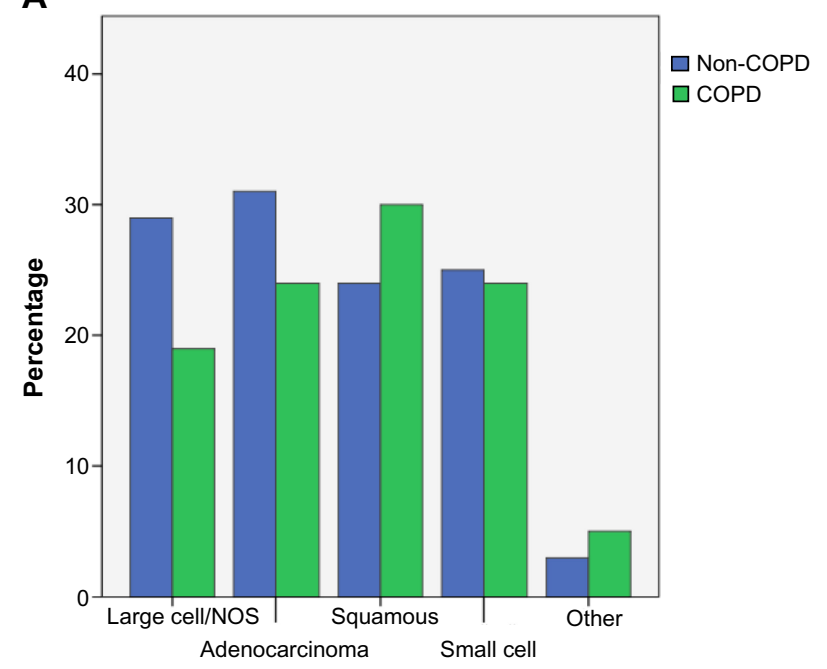

B

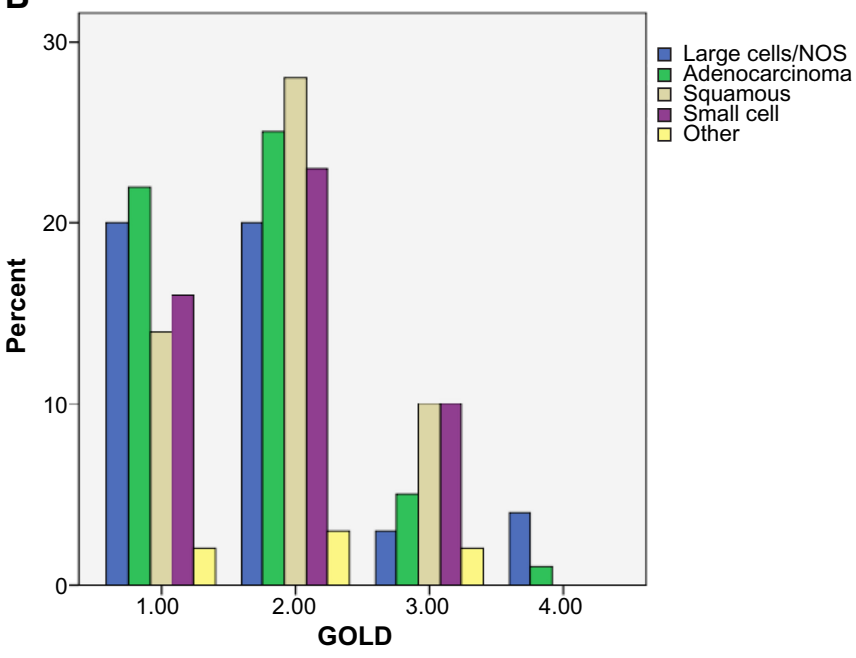

Figure I Pathological distribution of lung cancer in the entire study population and according to GOLD severity in COPD patients. Notes: (A) The entire study population; (B) GOLD severity in COPD patients.

Abbreviations: NOS, not otherwise specified; COPD, chronic obstructive pulmonary disease; GOLD, Global Initiative for Chronic Obstructive Lung Disease. 


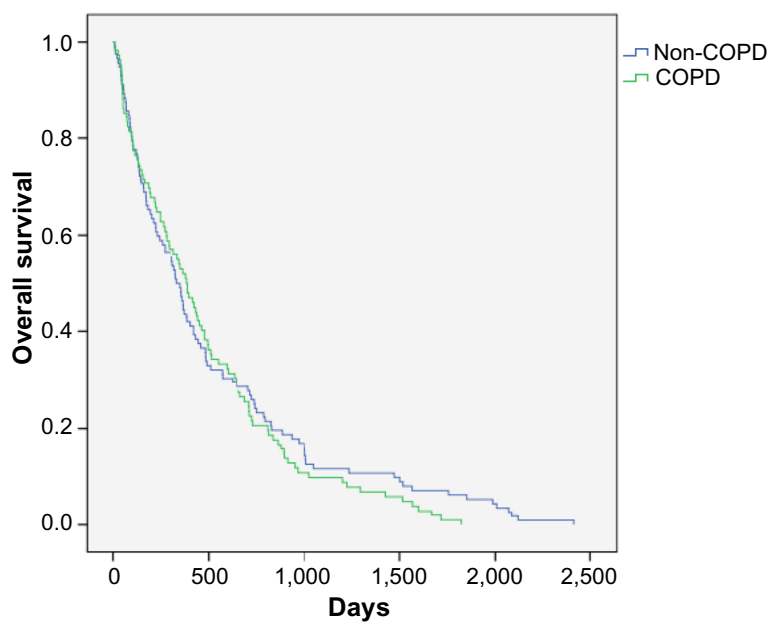

Figure 2 Kaplan-Meier curve of overall survival in COPD and non-COPD patients.

Note: There were no significant differences between both populations (log-rank [Mantel-Cox], $P=0.65$ ).

Abbreviation: COPD, chronic obstructive pulmonary disease.

LC, although the reasons why some subjects develop LC and some develop COPD when exposed to similar environmental challenges remain unresolved. ${ }^{17}$ Despite this gap, it is clear that there is an association between these complex diseases. However, what remains unsolved is how to use this information to the benefit of individual patients.

LC in COPD patients is a real problem since mortality studies of patients with COPD suggest that $20 \%-30 \%$ of patients die from LC. ${ }^{18}$ Our data show that $\sim 50 \%$ of LC cases have coexisting COPD, which confirms that a disproportionate number of $\mathrm{LC}$ cases occur in smokers with pre-existing COPD when compared with those with normal lung function. ${ }^{19,20}$

In this context, one thing that should be addressed is how important COPD is in patients with LC. Once the patients are diagnosed with LC, and if they are in the early stages, they are generally treated with curative intent using surgery, radiotherapy, and chemotherapy, or using a combined modality approach. ${ }^{21}$ Several studies have focused on this special issue since the concomitant coexistence of COPD might limit treatment with surgery. López-Encuentra et $\mathrm{a}^{22}$ analyzed the characteristics of COPD and non-COPD patients, as well as the possible prognostic value of this comorbidity over a sample of 2,994 LC nonmicrocytic cases surgically treated in hospitals participating in the Bronchogenic Carcinoma Cooperative Group of the Spanish Society of Pneumology and Thoracic Surgery. This study showed that such an association may have deleterious prognostic value in patients presenting with both diseases. The effect is observed 2 years after surgical resection, and in COPD, this effect is directly related to functional severity. Other authors that also investigated the comorbidity impact in nonmicrocytic resected LC found a higher mortality rate in COPD patients when compared with non-COPD patients. ${ }^{23}$ Therefore, by and large, the prognosis for patients with COPD and LC is worse than that of patients with LC without COPD. ${ }^{14,24}$ Certainly, there are patients in whom standard surgery is denied, offering only limited resection or nonsurgical treatment such as radiation therapy, radiofrequency ablation, stereotactic body radiotherapy, or cryotherapy because of impaired pulmonary function. ${ }^{25-27}$ These options might result in poorer survival and increased rates of local recurrence when compared with surgical treatment.

In common clinical practice, LC (both the small cell and nonsmall cell types) is usually diagnosed at an advanced stage, making it one of the most deadly forms of cancer. For patients with T4 extension, N2-N3 disease (stage 3B), or M1 (stage 4), surgical resection is not generally recommended. In a large population with 67,725 cases of nonsmall cell lung cancer that were submitted to the staging database, only 9,137 (13\%) cases were surgically managed ${ }^{28}$ Therefore, at diagnosis, most patients with LC have advanced disease that generally requires the use of systemic therapies in an effort to improve overall survival while maintaining quality of life. Although over $10 \%$ of patients can expect to be "cured" - who survive 5 years after diagnosis with

Table 2 HRs for overall survival according to main clinicopathological variables

\begin{tabular}{|c|c|c|c|c|}
\hline & $\begin{array}{l}\text { Univariate HR } \\
(95 \% \mathrm{Cl})\end{array}$ & $P$-value & $\begin{array}{l}\text { Multivariate } \mathbf{H R}_{\text {adj }} \\
(95 \% \mathrm{Cl})\end{array}$ & $P$-value \\
\hline Age & $1.00(0.99-1.01)$ & 0.89 & $1.00(0.99-1.01)$ & 0.94 \\
\hline Sex & $0.82(0.6 \mathrm{I}-\mathrm{I} .12)$ & 0.21 & I.34 (0.8I-2.22) & 0.26 \\
\hline Stage (3B versus 4 ) & $0.61(0.48-0.78)$ & $<0.001$ & $0.67(0.50-0.89)$ & 0.006 \\
\hline ECOG & $1.32(1.17-1.50)$ & $<0.001$ & $1.33(1.11-1.59)$ & 0.002 \\
\hline Pack/years & I (0.99-I.00) & 0.26 & I (0.99-I.00) & 0.92 \\
\hline COPD & $1.12(0.85-1.47)$ & 0.42 & $1.20(0.83-1.50)$ & 0.46 \\
\hline Histology & $1.22(1.01-1.46)$ & 0.04 & $1.06(0.94-1.20)$ & 0.36 \\
\hline
\end{tabular}

Abbreviations: $\mathrm{HR}$, hazard ratio; $\mathrm{Cl}$, confidence interval; $\mathrm{HR}_{\text {adj; }}$ adjusted hazard ratio; $\mathrm{ECOG}$, Eastern Cooperative Oncology Group; COPD, chronic obstructive pulmonary disease. 
no evidence of the cancer having returned - all patients can benefit from palliative treatment, which can improve the quality of survival. In fact, although very limited, the main improvement in the management of LC in recent years relates to palliative care.

The patients with advanced metastatic disease may achieve improved survival and the palliation of symptoms with chemotherapy, targeted agents, and other supportive measures. Treatment options for patients are determined by histology, tumor stage, as well as by the general health and comorbidities of the patient. In this specific population that, in our study, at the moment of diagnosis, represented the $69 \%$, we did not find significant differences in overall survival between COPD and non-COPD patients. In fact, overall, the presence of COPD did not negatively influence the quality of life of patients, so our treatment was selected according to NCCN guidelines without taking into consideration the presence of COPD.

In contrast with our data, Abal Arca et $\mathrm{a}^{29}$ found that in a large population of 996 patients with $\mathrm{LC}$, the risk of death was significantly higher at stages $3 \mathrm{~B}$ and 4 , and in the absence of surgery and chemotherapy; but, astonishingly, survival was significantly higher in COPD patients. To explain this result, the authors suggest some kind of diagnostic bias in this population due to the fact that COPD patients may be diagnosed in earlier stages. However, in an adjusted Cox regression model used for significant variables in the bivariate analysis, only stage and treatment remained in the final model. COPD, on the other hand, was not statistically significant.

Previous series have observed a progressive tendency toward a cytohistological diagnosis of adenocarcinoma in the general population. ${ }^{13}$ In our study, there was a nonsignificant trend for a higher percentage of adenocarcinoma/ large cell carcinoma in non-COPD and GOLD 1 patients, and in squamous and small cell cancer patients in GOLD 2-4. Tobacco smoking is a risk factor for any histological type of $\mathrm{LC}$, but it has been described that this association is stronger with squamous cell carcinoma, small cell carcinoma, and large cell carcinoma than with adenocarcinoma. In a study of Papi et al,,$^{30}$ the presence of COPD increased a patient's risk for developing squamous cell carcinoma by four times. These results have been confirmed by other authors that also found a better association between poor lung function and squamous cell carcinoma or microcytic carcinoma when compared with adenocarcinoma. ${ }^{31}$ This point is particularly relevant since nowadays, chemotherapy and new targeted drugs are strongly associated to histology. ${ }^{13}$

\section{Study limitations}

First, most of our patients with COPD were GOLD 1 and 2. Although we cannot exclude some impact in patients with severe airflow deterioration, the Pearson correlation coefficient between FEV1, as a percent of the predicted value, and overall survival was very low, suggesting that collateral factors other than the degree of airflow limitation are mainly responsible in the prognosis of most COPD patients with advanced LC.

Second, at present, the overall survival of patients with stages $3 \mathrm{~B}$ and 4 is very limited, and this could explain the absence of a clinical impact of COPD; however, survival is changing with new pharmacological approaches. These results should be reassessed if significant changes occur in the survival of patients with advanced LC.

\section{Conclusion}

We conclude that in the current study, when using standard care, COPD does not have a significant impact on the overall survival of advanced LC patients (stages $3 \mathrm{~B}$ and 4).

\section{Disclosure}

The authors report no conflicts of interest in this work.

\section{References}

1. Alberg AJ, Brock MV, Samet JM. Epidemiology of lung cancer: looking to the future. J Clin Oncol. 2005;23(14):3175-3185.

2. Buist AS, McBurnie MA, Vollmer WM, et al; BOLD Collaborative Research Group. International variation in the prevalence of COPD (the BOLD Study): a population-based prevalence study. Lancet. 2007;370(9589):741-750.

3. Loganathan RS, Stover DE, Shi W, Venkatraman E. Prevalence of COPD in women compared to men around the time of diagnosis of primary lung cancer. Chest. 2006;129(5):1305-1312.

4. Congleton J, Muers MF. The incidence of airflow obstruction in bronchial carcinoma, its relation to breathlessness, and response to bronchodilator therapy. Respir Med. 1995;89(4):291-296.

5. Løkke A, Lange P, Scharling H, Fabricius P, Vestbo J. Developing COPD: a 25 year follow up study of the general population. Thorax. 2006;61(11):935-939.

6. Sekine Y, Yamada Y, Chiyo M, et al. Association of chronic obstructive pulmonary disease and tumor recurrence in patients with stage IA lung cancer after complete resection. Ann Thorac Surg. 2007;84(3): 946-950.

7. Sekine Y, Kesler KA, Behnia M, Brooks-Brunn J, Sekine E, Brown JW COPD may increase the incidence of refractory supraventricular arrhythmias following pulmonary resection for non-small cell lung cancer. Chest. 2001;120(6):1783-1790.

8. Algar FJ, Alvarez A, Salvatierra A, Baamonde C, Aranda JL, López-Pujol FJ. Predicting pulmonary complications after pneumonectomy for lung cancer. Eur J Cardiothorac Surg. 2003;23(2):201-208.

9. Sekine Y, Behnia M, Fujisawa T. Impact of COPD on pulmonary complications and on long-term survival of patients undergoing surgery for NSCLC. Lung Cancer. 2002;37(1):95-101.

10. Kondo R, Yoshida K, Eguchi T, et al. Clinical features of lung cancer in smokers with light and mild chronic obstructive pulmonary disease: a retrospective analysis of Japanese surgical cases. Eur J Cardiothorac Surg. 2011;40(6):1439-1443. 
11. The Cooperative Group on Bronchogenic Carcinoma of SEPAR (GCCB-S). Sociedad Español de Neumología y Cirugía Torácica. [The surgery of bronchogenic carcinoma in Spain. A descriptive study]. Arch Bronconeumol. 1995;31(6):303-309. Spanish.

12. Gómez Sebastián G, Güell Rous R, González Valencia A, Fibla Alfara JJ, Estrada Saló G, León González C. [Impact of a rescue program on the operability of patients with bronchogenic carcinoma and chronic obstructive pulmonary disease]. Arch Bronconeumol. 2007;43(5):262-266. Spanish.

13. National Comprehensive Cancer Network [homepage on the Internet]. National Comprehensive Cancer Network. Fort Washington, PA: National Comprehensive Cancer Network; 2014. Available from: http://www.nccn.org. Accessed March 25, 2014.

14. Tammemagi CM, Neslund-Dudas C, Simoff M, Kvale P. Impact of comorbidity on lung cancer survival. Int J Cancer. 2003;103(6): 792-802.

15. Quanjer PH, editor. Standardized lung function testing. Report of Working Party Standardization of Lung Function Tests. European Community for Coal and Steel. Bull Eur Physiopathol Respir. 1983;19(Suppl 5):1-95.

16. Global Initiative for Chronic Obstructive Lung Disease [homepage on the Internet]. Global Initiative for Chronic Obstructive Lung Disease. Available from: http://www.goldcopd.com/. Accessed March 25, 2014.

17. Celli BR. Chronic obstructive pulmonary disease and lung cancer: common pathogenesis, shared clinical challenges. Proc Am Thorac Soc. 2012;9(2):74-79.

18. Calverley PM, Anderson JA, Celli B, Ferguson GT, Jenkins C, Jones $\mathrm{PW}$, et al. Salmeterol and fluticasone propionate and survival in chronic obstructive pulmonary disease. $N$ Engl J Med. 2007;356:775- 789.

19. Lung Health Study Research Group. Effect of inhaled triamcinolone on the decline in pulmonary function in chronic obstructive pulmonary disease. N Engl J Med. 2000;343(26):1902-1909.

20. Young RP, Hopkins RJ, Christmas T, Black PN, Metcalf P, Gamble GD. COPD prevalence is increased in lung cancer, independent of age, sex and smoking history. Eur Respir J. 2009;34(2):380-386.

21. National Institute for Health and Care Excellence [webpage on the Internet]. Lung cancer: the diagnosis and treatment of lung cancer. London, UK: National Institute for Health and Care Excellence; 2011. Available from: http://Guidance.nice.org.uk/cg121. Accessed March 25, 2014.
22. López-Encuentra A, Astudillo J, Cerezal J, Gonzalez-Aragoneses F, Novoa N, Sánchez-Palencia A; Bronchogenic Carcinoma Cooperative Group of the Spanish Society of Pulmonary and Thoracic Surgery (GCCB-S). Prognostic value of chronic obstructive pulmonary disease in 2994 cases of lung cancer. Eur J Cardiothorac Surg. 2005;27(1): $8-13$.

23. Battafarano RJ, Piccirillo JF, Meyers BF, et al. Impact of comorbidity on survival after surgical resection in patients with stage I non-small cell lung cancer. J Thorac Cardiovasc Surg. 2002;123(2):280-287.

24. Kiri VA, Soriano J, Visick G, Fabbri L. Recent trends in lung cancer and its association with COPD: an analysis using the UK GP Research Database. Prim Care Respir J. 2010;19(1):57-61.

25. Rosenthal SA, Curran WJ, Herbert SH, et al. Clinical stage II non-small cell lung cancer treated with radiation therapy alone. The significance of clinically staged ipsilateral hilar adenopathy (N1 disease). Cancer. 1992;70(10):2410-2417.

26. Choe YH, Kim SR, Lee KS, et al. The use of PTC and RFA as treatment alternatives with low procedural morbidity in non-small cell lung cancer. Eur J Cancer. 2009;45(10):1773-1779.

27. McGarry RC, Papiez L, Williams M, Whitford T, Timmerman RD. Stereotactic body radiation therapy of early-stage non-small-cell lung carcinoma: phase I study. Int J Radiat Oncol Biol Phys. 2005;63(4): $1010-1015$.

28. Chansky K, Sculier JP, Crowley JJ, Giroux D, Van Meerbeeck J, Goldstraw P; International Staging Committee and Participating Institutions. The International Association for the Study of Lung Cancer Staging Project: prognostic factors and pathologic TNM stage in surgically managed non-small cell lung cancer. J Thorac Oncol. 2009;4(7):792-801.

29. Abal Arca J, Parente Lamelas I, Almazán Ortega R, Blanco Pérez J, Toubes Navarro ME, Marcos Velázquez P. [Lung cancer and COPD: a common combination]. Arch Bronconeumol. 2009;45(10):502-507. Spanish.

30. Papi A, Casoni G, Caramori G, et al. COPD increases the risk of squamous histological subtype in smokers who develop non-small cell lung carcinoma. Thorax. 2004;59(8):679-681.

31. Nomura A, Stemmermann GN, Chyou PH, Marcus EB, Buist AS. Prospective study of pulmonary function and lung cancer. Am Rev Respir Dis. 1991;144(2):307-311.
International Journal of COPD

\section{Publish your work in this journal}

The International Journal of COPD is an international, peer-reviewed journal of therapeutics and pharmacology focusing on concise rapid reporting of clinical studies and reviews in COPD. Special focus is given to the pathophysiological processes underlying the disease, intervention programs, patient focused education, and self management protocols.

\section{Dovepress}

This journal is indexed on PubMed Central, MedLine and CAS. The manuscript management system is completely online and includes a very quick and fair peer-review system, which is all easy to use. Visit $\mathrm{http} / / / \mathrm{www}$. dovepress.com/testimonials.php to read real quotes from published authors. 